\title{
Facile and Sensitive Epifluorescent Silica Nanoparticles for the Rapid Screening of EHEC
}

\author{
Pravate Tuitemwong, ${ }^{1}$ Nut Songvorawit, ${ }^{2}$ and Kooranee Tuitemwong ${ }^{2}$ \\ ${ }^{1}$ Department of Microbiology, Food Safety Center, Faculty of Science, King Mongkut's University of Technology Thonburi, \\ Bangkok 10140, Thailand \\ ${ }^{2}$ Department of Microbiology, Kasetsart University, Bangkok 10900, Thailand
}

Correspondence should be addressed to Kooranee Tuitemwong; fscikrt@ku.ac.th

Received 3 January 2013; Accepted 21 April 2013

Academic Editor: Mohamed Bououdina

\begin{abstract}
Copyright (C) 2013 Pravate Tuitemwong et al. This is an open access article distributed under the Creative Commons Attribution License, which permits unrestricted use, distribution, and reproduction in any medium, provided the original work is properly cited.

This study was to develop antibodies conjugated fluorescent dye-doped silica nanoparticles (FDS-NPs) aiming to increase signals for the rapid detection of Escherichia coli O157:H7 with glass slide method. The FDS-NPs were produced with microemulsion/solgel techniques resulting in spherical in shape with $47 \pm 6 \mathrm{~nm}$ in diameter. The particles showed high intensity and stable orange color Rubpy luminescent dye. The XRD spectrum showed a broad diffraction peak in the range of $18-30^{\circ}\left(\right.$ centered at $\left.22^{\circ}\right)$ indicating an amorphous structure. Surface modifications for bioconjugation with affinity chromatography purified (IgGs) antibodies were successful. The properties were evident from FTIR spectra at $1631.7 \mathrm{~cm}^{-1}$. Results indicated that nanoparticles could attach onto cells of $E$. coli O157:H7 coated on a glass slide, and give distinctively bright color under epifluorescence microscope (400x). It was shown that FDS-NPs could detect a very low amount of cells of E. coli O157:H7 (16 CFU in $10 \mathrm{ml})$ in $60 \mathrm{~min}$. The phosphate buffered saline (PBS) with ionic strength of 1.70 gave zeta potential of good particle dispersion $(-40 \mathrm{mV})$. This work demonstrated that highly sensitive bioconjugated E. coli O157:H7 FDS-NPs were successfully developed with a potential to be used for the rapid detection of E. coli $\mathrm{O} 157: \mathrm{H} 7$ in foods.
\end{abstract}

\section{Introduction}

Rapid detection and identification of pathogens are of great importance for medical and food analyses. Traditional microbiological methods of detecting and enumerating bacteria require several days to yield reliable results. In many cases, the products have already been used by the consumers before the analyses are completed. Alternative and rapid assays based on different microbiological methods are constantly developed [1]. The effective testing of bacteria requires methods of analysis that meet a number of challenging criteria. Time and sensitivity of analysis are the most important limitations related to the usefulness of microbiological testing. The detection methods must give rapid results and highly sensitive since the presence of even a single pathogenic organism in the body or food may be an infectious dose [2]. To achieve good detections, fluorescent labeling probes are among the most popular methods. However, the traditional fluorophore such as fluorescein isothiocyanate (FITC) is not photostable in addition to the problem of relatively low fluorescence intensity [3]. Fluorescent-doped silica nanoparticles (FDS-NPs) have been developed [4]. The advantages of these particles are high intensity of the fluorescent signal, high photostability, high solubility, no toxicity, and efficient conjugation with various biomolecules because the silica surface is simple to modify. In this experiment, we synthesized, characterized and performed amine modification the FDS-NPs for the rapid detection of E. coli O157:H7. The aim was to increase the fluorescent signals surrounding E. coli $\mathrm{O} 157: \mathrm{H} 7$ cells to the detection level rather than increasing cell numbers which requires much longer time for growth, thereby significantly reduces the detection time.

\section{Materials and Methods}

2.1. Preparation of Purified IgGs. Purified IgGs against E. coli O157:H7 was prepared from concentrated E. coli O157:H7 
rabbit polyclonal antiserum using affinity chromatography method. Slide agglutination test was used to confirm efficiency of the antiserum against E. coli O157:H7.

2.1.1. Preparation of Antiserum. E. coli O157:H7 polyclonal antiserum was obtained from S\&N Laboratory, Bangkok, Thailand. It was diluted with $0.85 \% \mathrm{NaCl}$ (ratio $1: 1$ ). Tris$\mathrm{HCl}(\mathrm{pH}$ 8.0) was added to maintain $\mathrm{pH}$, and then the antiserum solution was precipitated with saturated $\left(\mathrm{NH}_{4}\right)_{2} \mathrm{SO}_{4}$. The sample was centrifuged at $8000 \times \mathrm{g}, 4^{\circ} \mathrm{C}$, for $30 \mathrm{~min}$ to collect the precipitate of mixed protein. The precipitate was dissolved in $1 \mathrm{x}$ PBS, $\mathrm{pH} 7.2$ to remove salt or other small molecules, and then the sample was further desalted using centrifugal ultrafiltration (Vivaspin 20; 30,000 MWCO) for 3 wash cycles. The product was filtered through a $0.20 \mu \mathrm{m}$ filter before purification step.

2.1.2. Purification of IgGs. The mixed protein solution was purified using protein A-sepharose affinity column (HiTrap Protein A HP, $5 \mathrm{~mL}$ ). The column was equilibrated with 5 column volumes of binding buffer $(20 \mathrm{mM}$ sodium phosphate buffer, $\mathrm{pH}$ 7.0). Then, the antiserum was applied and washed with 5-10 column volumes of binding buffer to remove impurities and unbound materials. The $1 \mathrm{~mL}$ fractions were collected and determined for amount of protein by UV absorption at $280 \mathrm{~nm}$. After that, the column was eluted with 5 column volumes of elution buffer $(0.1 \mathrm{M}$ citric acid, $\mathrm{pH}$ 3.0). The fractions of IgGs were neutralized with tris- $\mathrm{HCl}$ ( $\mathrm{pH} 9.0$ ) and pooled together. It was desalted using Vivaspin 20 ultracentrifugation. The purified IgGs was further determined for protein concentration with Lowry method [5] and for purity using sodium dodecyl sulfate polyacrylamide gel electrophoresis (SDS-PAGE).

2.2. Preparation of Test Organisms. In this study, E. coli O157:H7 was used as a target organism for the detection with FDS-NPs and MNPs, while E. coli ATCC 8739, E. aerogenes, P. mirabilis, S. Typhimurium DMST 16809, B. cereus ATCC 11778, and S. aureus ATCC 25923 were used as challenge organisms to study the specificity of the nanoparticles. All test bacteria were grown in TSB at $37^{\circ} \mathrm{C}$ for $24 \mathrm{~h}$ before experiment. The bacterial inoculum was spreaded on PCA plate using sterile swab. Then, sterile glass slide was placed on the surface of that agar medium and incubated at $37^{\circ} \mathrm{C}$ for $8 \mathrm{~h}$ to allow the bacteria to grow and attach on the glass slide. After incubation, the slide was gently washed to remove unbound cells before detection with FDS-NPs.

\subsection{Fluorescent Dye-Doped Silica Nanoparticles}

2.3.1. Preparation of FDS-NPs. The method was modified from that described by Tansub et al. [6]. Briefly, cyclohexane, 1-hexanol, Triton X-100, 20 mM Rubpy dye solution, TEOS, and $30 \% \mathrm{NH}_{4} \mathrm{OH}$ were mixed together and stirred $(1500 \mathrm{rpm})$ in a $50 \mathrm{~mL}$ flask for $24 \mathrm{~h}$. After the reaction was completed, FDS-NPs were separated from the solution with acetone precipitation. FDS-NPs were then washed with 95\% ethanol and distilled water several times to remove the solvent and surfactant. The nanoparticles were dried in hot air oven at $100^{\circ} \mathrm{C}$ for $48 \mathrm{~h}$. After that, the nanoparticles were ground and stored in dark bottles.

2.3.2. Characterization of FDS-NPs. Characterization of FDS-NPs was carried out as described by Tansub et al. [6]. Size and morphology of FDS-NPs were examined under TEM. Elemental components were analyzed by using scanning electron microscope with SEM-EDS. Particle structure was analyzed by using XRD ( $40 \mathrm{kV}$, angle $4-45$ degree, increment 0.02 degree/step, and scan speed $0.3 \mathrm{sec} / \mathrm{step}$ ). Optical properties, excitation, and emission spectra of Rubpy dye and the FDS-NPs were obtained using the spectrofluorometer for investigation. The photostability was obtained from the fluorescence intensity measured with spectrofluorometer every $5 \mathrm{~min}$.

\subsubsection{Surface Modification and Coating of IgGs onto FDS-NPs}

Surface Modification. Amino group modification of FDSNPs was carried out before coating with IgGs. FDS-NPs of $2 \mathrm{mg} / \mathrm{mL}$ was suspended in $1 \mathrm{mM}$ acetic acid containing $5 \%$ APTES and stirred at room temperature $\left(30^{\circ} \mathrm{C}\right)$ for $3 \mathrm{~h}$. Then, the amino-functionalized FDS-NPs were washed with distilled water. The nanoparticles were stored in a dark bottle at $4^{\circ} \mathrm{C}$. They were characterized by FT-IR spectrometer to confirm the existence of free amino group on the particle surface. The sample was prepared by milling the FDS-NPs with $\mathrm{KBr}$ (ratio 1:100) to form a very fine powder. The powder was then compressed to a thin pellet before it was analyzed with FT-IR spectrometer at midinfrared wave (wave number $4000-400 \mathrm{~cm}^{-1}$ ) with resolution of $4.0 \mathrm{~cm}^{-1}$ and number of scan of 32 .

Coating of IgGs onto FDS-NPs. The suspension of aminofunctionalized FDS-NPs in 1x PBS (2 mg/mL, pH 7.4) with $2.5 \%$ glutaraldehyde was stirred at room temperature for $2 \mathrm{~h}$. The particles were separated by centrifugation and washed with PBS to remove free glutaraldehyde. After that, they were redispersed into $1 \mathrm{x}$ PBS. The glutaraldehyde treated FDSNPs were then incubated with purified IgGs against E. coli O157:H7 by adjusting the final concentration of FDS-NPs and IgGs to 2 and $0.1 \mathrm{mg} / \mathrm{mL}$, respectively. The suspension was divided to two portions. One was incubated at $4^{\circ} \mathrm{C}$ and the other at $37^{\circ} \mathrm{C}$ to study the effects of temperature. The amount of protein on the particles at $3,6,12$, and $24 \mathrm{~h}$ of incubation was determined by Lowry method [5]. Noncovalent binding of IgGs on particles was also studied using unmodified FDSNPs incubated with IgG solution at the same conditions as described above.

2.3.4. Zeta Potential Measurement. Effect of ionic strength on aggregations of FDS-NPs in terms of zeta potential was investigated. Uncoated and IgG-coated FDS-NPs were dispersed in $0.1 \mathrm{x}$ PBS $(0.2 \mathrm{mg} / \mathrm{mL})$, pH 7.4 (a standard solution), and that containing different $\mathrm{NaCl}$ concentrations. FDS-NP 
suspension was analyzed for zeta potential with zeta meter. The ionic strength $(I)$ of a solution was calculated by (1):

$$
I=\frac{1}{2} \sum_{i=1}^{n} c_{i} z_{i}^{2}
$$

where $c_{i}$ is a molar concentration of $i$ th ion present in the solution and $z_{i}$ is its charge.

Stability and dispersibility of particles at each zeta potential (in the unit of $\mathrm{mV}$ ) can be interpreted as follows. The values from -30 to +30 are considered unstable and tend to aggregate, from -40 to -30 and +40 to +30 are moderately stable, -60 to -40 and +60 to +40 are good stability, and the values beyond -60 or +60 indicated excellent stability [7].

2.3.5. Testing with Bacteria. FDS-NPs were tested with targets on the effects of incubation time and particle concentration and with nontarget bacteria in terms of specificity. All samples were stained with DAPI (a fluorescent dye which binds to DNA of organisms and exhibits blue luminescence when it is excited with UV light) before observation to easily distinguish between particle bound and unbound cells. The samples were observed under epifluorescence microscope with UV and blue light excitation. Each treatment of all experiments was performed in triplicate.

Effect of Incubation Time. Glass slide with E. coli O157:H7 was flooded with $0.5 \mathrm{~mL}$ of IgG-coated FDS-NPs $(0.2 \mathrm{mg} / \mathrm{mL})$ and incubated at room temperature at various reaction times $(15,30,60,120$, and $180 \mathrm{~min})$. After the incubation, the slide was washed to remove unbound particles and then was stained with DAPI solution. The slide was observed under epifluorescence microscope. Capture efficiency of FDS-NPs at each incubation time was assessed as the percentage of bacterial cells attached by particles to the total bacterial cells in the slide in the same field for 3-5 fields. Capture efficiency was calculated by (2):

$$
\text { Capture efficiency }(\%)=\left(\frac{N_{a}}{N_{0}}\right) \times 100 \text {, }
$$

where $N_{a}$ is number of bright orange dots (FDS-NPs bound cells) and $N_{0}$ is the sum of bright orange and blue dots (total cells) which were found in the microscopic field.

Effect of FDS-NP Concentration. IgG-coated FDS-NPs were dispersed and diluted to $0.2,0.5$, and $1.0 \mathrm{mg} / \mathrm{mL}$ in $1 \mathrm{x}$ PBS ( $\mathrm{pH}$ 7.4). Then, glass slide with E. coli O157:H7 was flooded with $0.5 \mathrm{~mL}$ of particle suspension and incubated for $60 \mathrm{~min}$ at room temperature. Then, it was washed with distilled water to remove unbound particles. The slide was stained with DAPI solution and observed under epifluorescence microscope. Capture efficiency of FDS-NPs at each concentration was calculated by (2). Nonspecific binding of FDS-NPs was also observed using uncoated FDS-NPs incubated with E. coli O157:H7.

Specificity. The specificity was tested using the same glass slide method but using non-E. coli O157:H7 bacteria with IgGcoated FDS-NPs. The attachment was considered nonspecific binding of the FDS-NPs.

\section{Results and Discussion}

3.1. Purification of Antiserum. E. coli O157:H7 polyclonal antiserum purchased from S\&A Reagent Lab was tested with suspension of E. coli O157:H7 and other bacteria. Positive result which refers to agglutination was obtained from $E$. coli O157:H7, while negative results were observed with E. coli ATCC 8739, E. aerogenes, $P$. mirabilis, S. typhimurium DMST 16809, B. cereus ATCC 11778, and S. aureus ATCC 25923. Results indicated that $E$. coli $\mathrm{O} 157: \mathrm{H} 7$ antiserum had adequate efficiency to use for further experiments.

3.2. Purification of IgGs. The antiserum had protein content of $56 \mathrm{mg} / \mathrm{mL}$. Because total protein of antiserum was $280 \mathrm{mg}$ $(56 \mathrm{mg} / \mathrm{mL}, 5 \mathrm{~mL})$ that was greater than the binding capacity of the protein-A sepharose affinity column (about $100 \mathrm{mg}$ IgGs), the E. coli O157:H7 antiserum was prior divided into 4 portions. Each portion was applied into column for 2 cycles. The target IgGs were obtained only from the first cycle of purification. None was detected from portions from the second cycle. Figure 1 shows amount of protein and IgGs of each fraction. For portions 1, 2, 3, and 4, IgG was collected from fractions 22 to 33 , from 29 to 40 , from 29 to 42 , and from 34 to 40 , respectively. The purified IgG was further examined for the purity by SDS-PAGE. The results confirmed its purity by showing two bands of heavy chain, $50 \mathrm{kDa}$, and light chain, $25 \mathrm{kDa}$ (Figure 2).

For this research, an E. coli O157:H7 antiserum from a rabbit was purified with protein A-sepharose affinity column. Protein A is a surface protein found in cell wall of Staphylococcus aureus. Protein A consists of six different regions, five of which show strong, specific binding for the Fc-part of IgG, leaving the antigen-binding sites free. Immobilized protein $\mathrm{A}$ can bind at least two molecules of IgG per molecule. When an antiserum was applied into a column, IgG will bind to protein A-sepharose, while other proteins do not. The binding of IgG and protein A can be broken by acidity of elution buffer.

3.3. Synthesis and Characterization of FDS-NPs. FDS-NPs were successfully synthesized by modified sol-gel reaction via water-in-oil microemulsion method. At the early step, the mixture was a homogeneous solution with clear orange color. After the reaction had passed $24 \mathrm{~h}$, there was no change in the mixture. But when acetone was added to isolate NPs, the mixture changed from clear orange solution to precipitate like a gel indicating that the formation of FDS-NPs has completed. The FDS-NPs were washed, dried, and ground. The obtained product was fine orange powder. The FDS-NPs were quite uniform in spherical shape with average sizes of $47 \pm 6$ and 


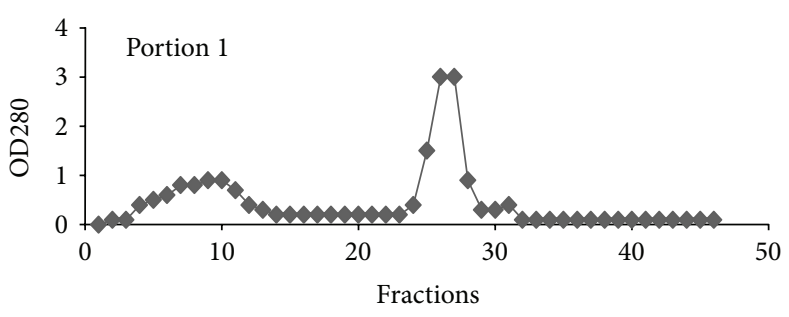

(a)

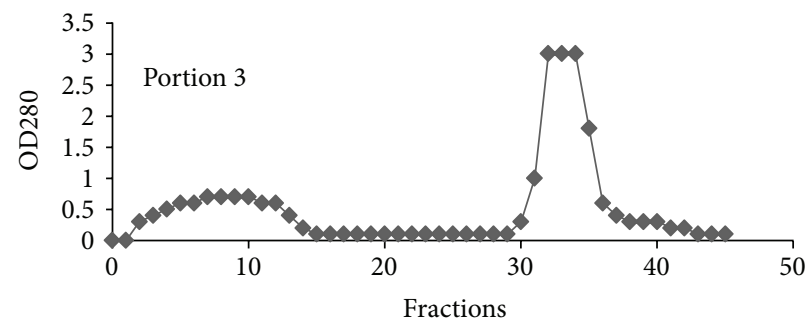

(c)

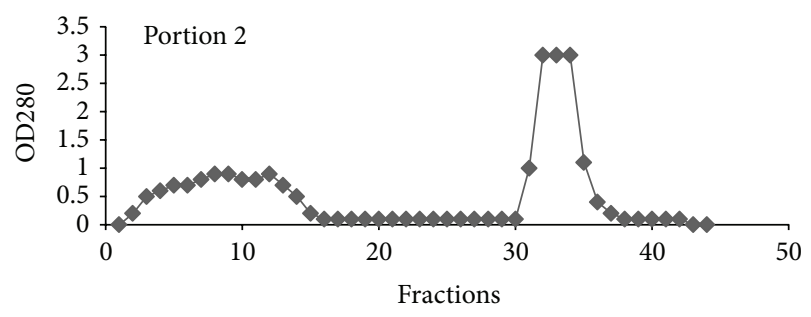

(b)

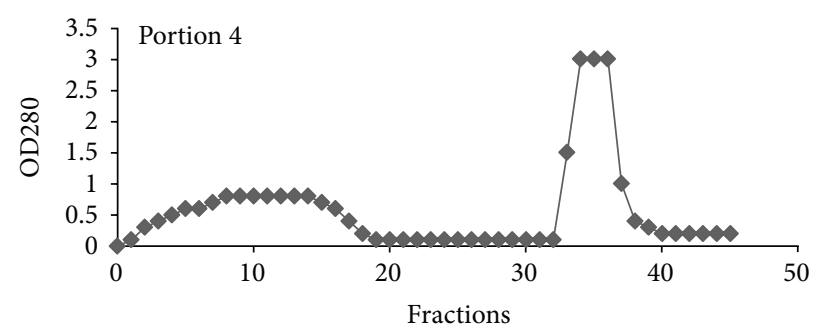

(d)

FIgUre 1: Purification of IgGs from E. coli O157:H7 antiserum.

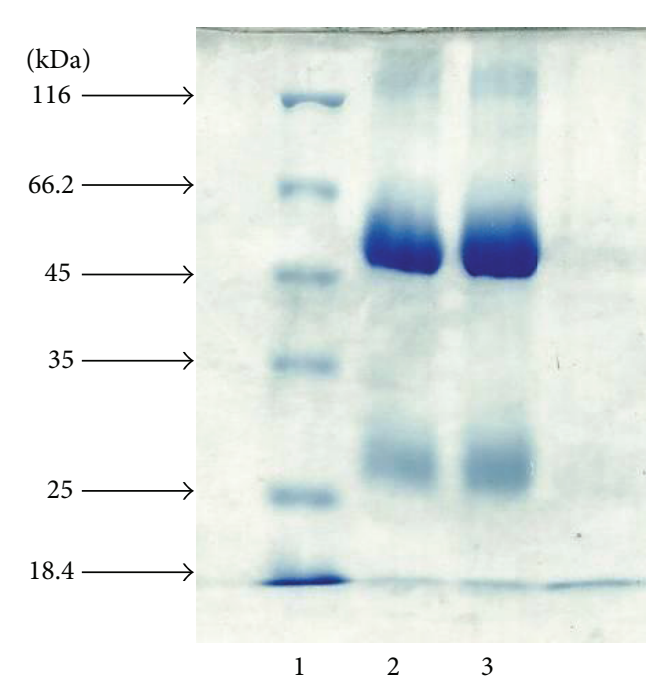

FIGURE 2: SDS-PAGE of the purified IgGs. Lane 1 is protein standard (ladder). Lanes 2 and 3 are IgGs from E. coli O157:H7 antiserum.

mode of $50 \mathrm{~nm}$ (Figure 3 ). The TEM image shows that FDSNPs were quite uniform in spherical shape.

In the synthesis of FDS-NPs, TEOS, as a precursor, reacts with water to form polymer of $\mathrm{SiO}_{2}$ or silica by solgel process [4]. A polymerization reaction is initiated by $\mathrm{NH}_{4} \mathrm{OH}$. In water-in-oil microemulsion, the aqueous phase is dispersed as microdroplets surrounded by a monolayer of surfactant and cosurfactant molecules (Triton X-100 and 1hexanol) in the continuous hydrocarbon phase (cyclohexane). The aqueous cores of microemulsion systems can serve as compartmentalized media for chemical reactions, as a microreactor for the synthesis of NPs [8]. In addition, the size of the NPs can be manipulated as needed, by changing the water-to-surfactant molar ratio $[6,9]$. While this reaction is

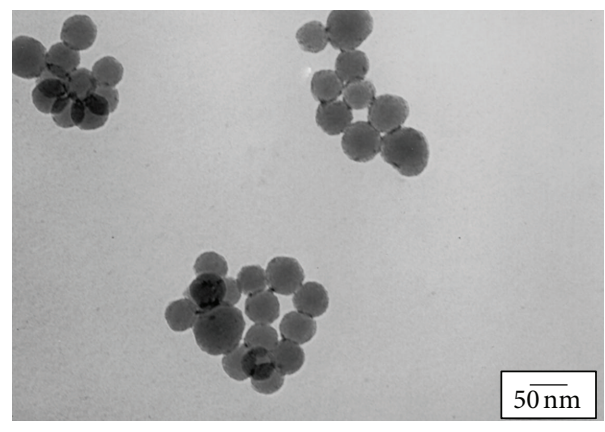

FIGURE 3: The TEM image of FDS-NPs at 160000x.

proceeding, a lot of Rubpy dye molecules, which are dissolved in water phase, are trapped inside a silica matrix. That makes this particles have a luminescence property.

3.4. Structure of FDS-NPs Using X-Ray Diffraction. The $\mathrm{SiO}_{2}$ materials can be divided into two states: the crystalline and amorphous. XRD measurement to characterize the structure of FDS-NPs was performed. The XRD spectrum (Figure 4) shows a broad diffraction peak in the range of $18-30^{\circ}$ (center at $22^{\circ}$ ), which indicates an amorphous structure [10-12]. In this study, XRD spectrum of FDSNPs did not match with any standard XRD pattern in the database of Inorganic Crystal Structure Database (ICSD). It is also reported that silicon dioxide is an amorphous solid which does not have a characteristic X-ray diffraction pattern (http://www.ltschem.com/sio2.htm).

3.5. Optical Properties of FDS-NPs: Excitation and Emission Spectra. The study of luminescence properties showed that both FDS-NPs and pure Rubpy had an excitation band in the range of UV light to blue light maximum with 


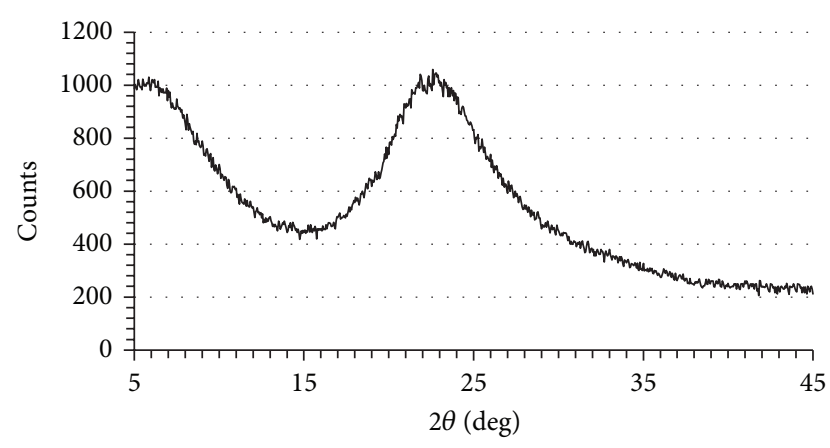

FIGURE 4: XRD spectrum of FDS-NPs.

the maximum excitation wavelength at $455 \mathrm{~nm}$ (Figure 6). Emission spectrum of FDS-NPs was the same as that of pure Rubpy dye, which had a maximum emission wavelength at $606 \mathrm{~nm}$ (the range of orange light) (Figure 7). These results indicated that the structure of silica did not change optical properties of fluorescent dye.

3.6. Photostability. The FDS-NPs were excited with UV light $(365 \mathrm{~nm})$ of mercury lamp (8W) for 60 min (Figure 6). After excitation for $60 \mathrm{~min}$, the FDS-NPs showed a slight decrease $(1.5 \%)$ of the emission intensity, while the emission intensity of pure Rubpy dye was decreased by $6 \%$. This study chose high hydrophilic Rubpy dye as an inorganic fluorescent dye. Therefore, it can dissolve in water and hence suit to be applied with FDS-NPs synthesis using water in oil microemulsion. The dye molecules appear to be more stable and well protected by FDS-NPs structure from photobleaching and photodegradation that often affect conventional dyes. Moreover, a large number of dye molecules incorporated inside a very small volume of silica particle made FDSNPs a very bright luminescence when excited (Figure 7). The maximum fluorescent intensity of dyes in the particles appears to be higher than that of the pure form because a large number of molecules were trapped in the FDS-NPs particles.

3.7. Elemental Components and Surface Modification of FDSNPs Particles. Elemental components of FDS-NPs product were characterized by SEM-EDS. The results showed that the elements of FDS-NPs comprised of Si (11.31\% atomic), $\mathrm{O}$ (64.43\% atomic), $\mathrm{Ru}(0.15 \%$ atomic), and C (24.11\% atomic). The existence of Ru confirmed that Rubpy dye was doped inside the particles. Carbon was also detected. Three possible presumptions for the existence of carbon in FDSNPs could be from either Rubpy dye molecules, alcohol from condensation reaction, or organic components which bound tightly with FDS-NPs. A large amount of oxygen higher than a general 1:2 atomic ratio of $\mathrm{SiO}_{2}$ was found in FDS-NPs. This suggested that the extra oxygen molecule was from $\mathrm{H}_{2} \mathrm{O}$ molecules which bound to the particles. This result was confirmed by the FT-IR spectra (data not shown), where the appearance of $\mathrm{H}_{2} \mathrm{O}$ was confirmed.

Based on the FTIR spectra of FDS-NPs with aminofunctionalized surface modification, it was found that the

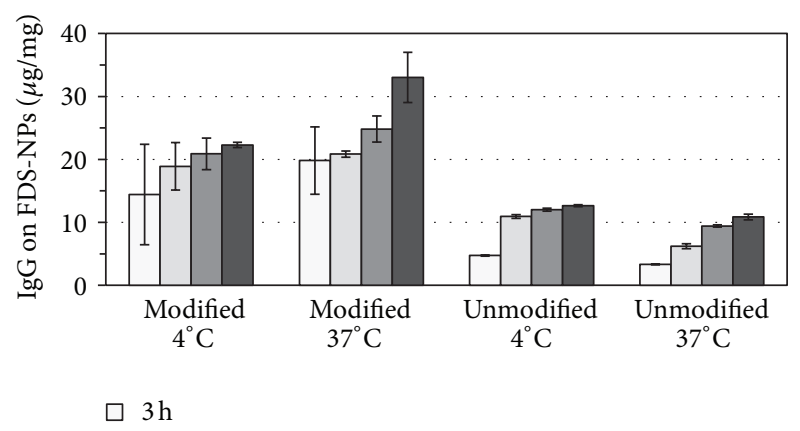

FIGURE 5: Amount of IgGs on FDS-NPs after incubation at various conditions.

amine group was successfully attached onto the particle surface. The wave numbers from 3400 to $3280 \mathrm{~cm}^{-1}$ represent $-\mathrm{NH}_{2}$ asymmetric and symmetric stretching vibrations. The wave numbers from 1650 to $1600 \mathrm{~cm}^{-1}$ represent $\mathrm{N}-\mathrm{H}$ bending vibration. Since IR bands that refer to $\mathrm{N}-\mathrm{H}$ bending vibration and $-\mathrm{NH}_{2}$ stretching vibration overlap with the IR bands of $-\mathrm{OH}$ groups and $\mathrm{C}-\mathrm{N}$ stretching vibration was overlapped with the absorption peak of $\mathrm{Si}-\mathrm{O}-\mathrm{Si}$ stretching vibration, it is difficult to distinguish between modified and unmodified FDS-NPs.

There were two points that were quite different between them. First, a broad IR band in the rage from 3600 to $3000 \mathrm{~cm}^{-1}$ generally refers to $\mathrm{O}-\mathrm{H}$ stretching vibrations of $\mathrm{Si}-\mathrm{OH}$ and adsorbed $\mathrm{H}_{2} \mathrm{O}$ [13-15]. This range also overlaps with the asymmetric and symmetric stretching vibrations of the $-\mathrm{NH}_{2}$ groups. From the result, this band of modified FDSNPs was wider than unmodified one. This can be explained by the absorption of amino group which was added into modified particles. Second, a band around the range from 1630 to $1600 \mathrm{~cm}^{-1}$ of modified particles was also wider than that of the unmodified particles $[13,14]$. Tansub et al. [6] found similar overlapping. The authors successfully confirmed the existence of amino group on particle surface by FT Raman.

3.8. Antibodies Conjugation (IgGs) with FDS-NPs. Effects of reaction temperature and time on coating IgG on FDS-NPs were determined from amount of immobilized protein on FDS-NPs. The high concentration of IgG solution $(100 \mu \mathrm{g} / \mathrm{mL})$ was incubated with amino-modified FDS-NPs to obtain the maximum IgG loading capacity of FDS-NPs. Protein assay by Lowry method was used for determining the remaining protein. The total protein concentration subtracted by the remaining protein yields the protein attached on FDS-NPs particles.

Results that showed average amount of immobilized IgGs on amino-modified FDS-NPs at $4^{\circ} \mathrm{C}$ for $3,6,12$, and $24 \mathrm{~h}$ were $14.20,18.90 .20 .89$, and $22.30 \mu \mathrm{g} / \mathrm{mg}$, respectively (Figure 5). Whereas at $37^{\circ} \mathrm{C}$, the immobilized IgGs on FDS-NPs were $19.83,20.85,24.83$, and $33.02 \mu \mathrm{g} / \mathrm{mg}$, respectively (Figure 5). The longer incubation time resulted in higher immobilized IgGs on FDS-NPs. Higher rates of immobilization were obtained from incubation at $37^{\circ} \mathrm{C}$ compared with that of $4^{\circ} \mathrm{C}$. Thus, condition of $37^{\circ} \mathrm{C}$ and $24 \mathrm{~h}$ was used as an appropriate 


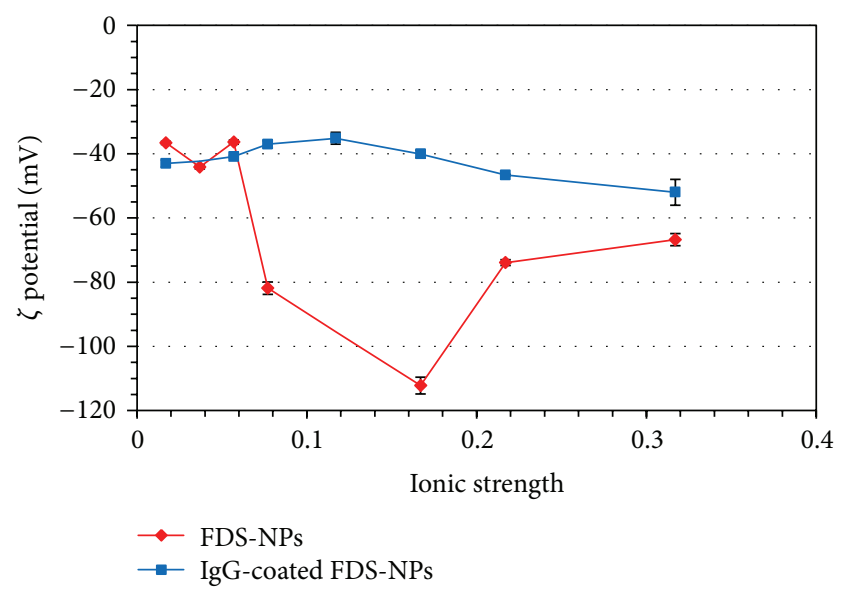

FIGURE 6: Zeta potential at various ionic strength of FDS-NPs (uncoated FDS-NPs) and IgG-coated FDS-NPs.

condition for IgG coating for subsequent experiments. The attachments were not significant at $4^{\circ} \mathrm{C}$, but the incubation at $37^{\circ} \mathrm{C}$ gave a significant increase of bound protein on FDSNPs. At $3 \mathrm{~h}$ incubation, for example, IgGs on particles were detected at much lower concentrations $(3.43 \mu \mathrm{g} / \mathrm{kg})$ than the IgGs on amino-modified FDS-NPs $(20 \mu \mathrm{g} / \mathrm{kg})$.

Since the immobilization of protein onto particles can occur via both physical and chemical approaches, noncovalent binding was also observed using unmodified FDS-NPs. The amount of IgGs after incubation for 3, 6, 12, and $24 \mathrm{~h}$ were $4.74,10.94,12.01$, and $12.65 \mu \mathrm{g} / \mathrm{mg}$ for incubation at $4^{\circ} \mathrm{C}$ and were $3.34,6.20,9.43$, and $10.86 \mu \mathrm{g} / \mathrm{mg}$ for incubation at $37^{\circ} \mathrm{C}$. It indicated that noncovalent binding may occur in this procedure due to electrostatic force, van der Waals interaction, or hydrogen bonding.

There are numerous techniques to choose to immobilize protein onto nanoparticle, depending on functional groups on the nanoparticle surface and biomolecules. In this case, FDS-NPs were modified to have amino groups on their surface that facilitate the bioconjugation with the target antibodies. Thus, glutaraldehyde, which is well known as a crosslinking reagent between two amino groups of protein, was used for FDS-NPs-IgGs conjugation. Two aldehyde groups at both sides of glutaraldehyde molecule are reactive groups that can bind to amino group via covalent bonding. This allowed IgGs to be immobilized on FDS-NPs. From the experiment, this technique is easy to manipulate, does not require many reagents, and has short time consumption with high efficiency.

3.9. Zeta Potential of FDS-NPs. Zeta potential is an electric potential in colloidal system. It is useful for prediction of dispersion stability of particles in solution since many factors, such as $\mathrm{pH}$, conductivity, type of ion, and ionic strength in a medium have an effect on this value. However, $\mathrm{pH} 7.4$ is the favorable $\mathrm{pH}$ for antigen-antibody interaction. Thus, only an effect of ionic strength to the zeta potential of FDS-NPs was studied.

Generally, zeta potential particles in the range from 30 to $-30 \mathrm{mV}$ will be unstable and tend to aggregate, that is, undesirable to any application, and they are more stable when the value is far from zero point. From the results, zeta potential of uncoated FDS-NPs at all ionic strengths was well below $-30 \mathrm{mV}$ (Figure 6), indicating that the FDSNPs were well dispersed and stable when ionic strength was 0.167. However, after FDS-NPs were coated with IgGs, the zeta potential of each ionic strength has changed, suggesting that these changes derived from an effect of IgGs coated on particle surface. The zeta potentials of IgG-coated FDS-NPs at all ion concentrations were about $-40 \mathrm{mV}$ and slightly decreased when ionic strength increased. This means the FDS-NPs are, moderately to well, dispersed in all conditions of this experiment. Although at high ion concentration, coated FDS-NPs had more stability. However, high ionic strength can cause the antibody to denaturalize, thereby decrease the efficiency of antigen-antibody interaction. Thus, ionic strength of 0.167 was considered as an appropriate condition for further experiment. However, the ionic strength (0.167) is approximate to the ionic strength of $1 \mathrm{x}$ PBS (ionic strength 0.17). Therefore, $1 \mathrm{x}$ PBS ( $\mathrm{pH} 7.4$ ) was used as a solution for further experiment.

3.10. Testing with Bacteria. The antibody conjugated FDSNPs were tested for their capturing ability of the target $E$. coli O157:H7 cells using glass slide method. The target cells exhibit bright orange color under epifluorescence microscope (Figure 7).

3.10.1. Effect of Incubation Time. Effects of incubation time were observed under epifluorescence microscope (Figure 7), and the targets were excited with both blue and UV lights to compare the ratio of bound and free cells. It was found that, the FDS-NPs gave distinctively bright color under epifluorescence microscope that facilitated the detection of target bacteria by increasing the signals not the cell numbers. The signals increment requires only $15-60 \mathrm{~min}$ to reach the detection level, while the cell growth requires $24-48 \mathrm{~h}$ to reach the detectable level from $10^{5}$ to $10^{8} \mathrm{cfu} / \mathrm{g}$.

The capture efficiency of FDS-NPs was 58.17\%, 74.48\%, $87.83 \%, 85.23 \%$, and $90.91 \%$ for $15,30,60,120$, and $180 \mathrm{~min}$, respectively. The longer incubation time resulted in the greater capture efficiency. However, when the incubation time had passed $120 \mathrm{~min}$, the amount of bacteria which were bound with FDS-NPs was not different from that of the $60 \mathrm{~min}$. This indicated that it reached to the maximum binding capacity of FDS-NPs. Thus, $60 \mathrm{~min}$ were assumed optimal incubation time for this experiment.

3.10.2. Effects of FDS-NP Concentration. E. coli $\mathrm{O} 157: \mathrm{H} 7$ cells were incubated with various concentrations of FDS-NPs. Capture efficiency of $0.2 \mathrm{mg} / \mathrm{mL}$ FDS-NPs was $87.31 \%$, while $0.5 \mathrm{mg} / \mathrm{mL}$ and $1.0 \mathrm{mg} / \mathrm{mL}$ FDS-NPs were $87.77 \%$ and $88.77 \%$ because $0.2 \mathrm{mg} / \mathrm{mL}$ FDS-NPs gave a percent capture closed to that of $1.0 \mathrm{mg} / \mathrm{mL}$ FDS-NPs. Hence, $0.2 \mathrm{mg} / \mathrm{mL}$ was used as the concentration of FDS-NPs in the subsequent experiments. Moreover, to ensure whether E. coli O157:H7 cells were captured by FDS-NPs via antigen-antibody interaction, uncoated FDS-NPs were incubated with the target bacteria 

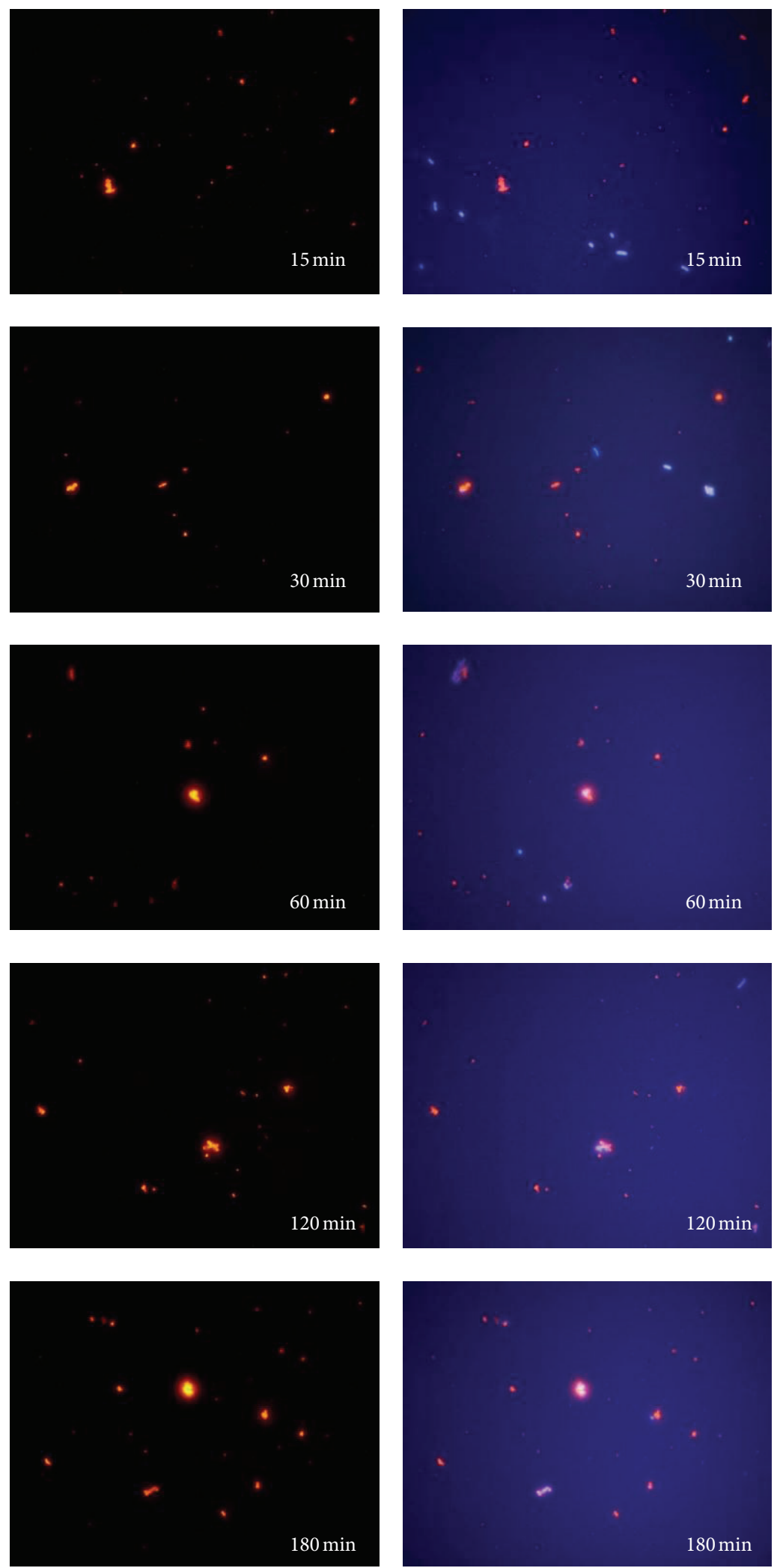

(a)

(b)

FIGURE 7: Fluorescence images at 1000x of E. coli O157:H7 incubated with IgG-coated FDS-NPs at various incubation times: (a) excited with blue light and (b) excited with UV light. 


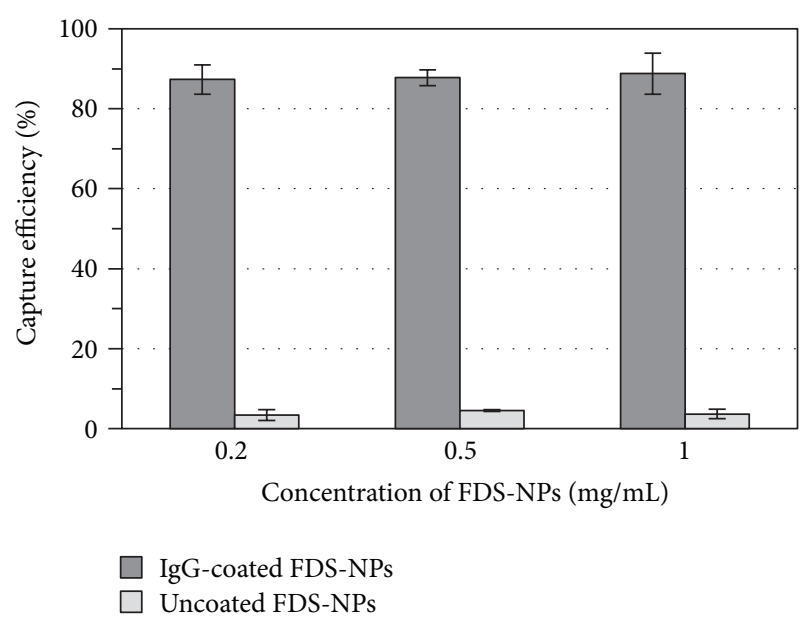

FIGURE 8: Effects of concentration of FDS-NPs on the binding efficiency of IgG-coated FDS-NPs with E. coli O157:H7.

as a control. The results showed that the capture efficiency of all trials were about 3\%-5\% indicating that few cells were captured by uncoated FDS-NPs (Figure 8). This capture was nonspecific binding and could occur by weak interaction between surface of bacterial cells and surface of FDS-NPs such as electrostatic force. However, for this experiment, it was confirmed that the bacterial cells were captured by IgGs on FDS-NP surface rather than other unspecific interactions.

\section{Conclusion}

This study demonstrated that the FDS-NPs nanoparticles prepared by microemulsion combined with sol-gel techniques were successful having spherical shape with nanosize $(40-50 \mathrm{~nm})$ with high photostability of luminescence $(1.5 \%$ decrease when excited with $8 \mathrm{~W}$ UV light for $60 \mathrm{~min})$. The nanoparticles were modified to add functional group (amino group) on their surface using APTES. Glutaraldehyde was used as crosslinker between IgGs and particle surface that allowed IgGs to coat on FDS-NPs. Loading capacity of IgGs on particle surface was about $33 \mu \mathrm{g} / \mathrm{mg}$ when incubated with IgGs at $37^{\circ} \mathrm{C}$ for $24 \mathrm{~h}$. IgG-coated FDS-NPs tended to create aggregates in the detection of targeted bacteria, while the detection of E. coli $\mathrm{O} 157: \mathrm{H7}$ on glass slide was successful. FDS-NPs could attach onto target organism and give distinctively bright color under fluorescence microscope. The detection of bacteria with this nanoparticle is very promising, though at low levels of the cells, due to their ability of amplify light signal in the detection step. Capture efficiency at $0.2 \mathrm{mg} / \mathrm{mL}$ FDS-NPs and $60 \mathrm{~min}$ incubation was $87.31 \%$. IgG-coated FDS-NPs had low cross-reaction to nontarget bacteria despite using polyclonal antibody with affinity purification.

\section{References}

[1] L. Vanne, M. Karwoski, S. Karppinen, and A. M. Sjöberg, "HACCP-based food quality control and rapid detection methods for microorganisms," Food Control, vol. 7, no. 6, pp. 263-276, 1996.
[2] D. Ivnitski, I. Abdel-Hamid, P. Atanasov, and E. Wilkins, "Biosensors for detection of pathogenic bacteria," Biosensors and Bioelectronics, vol. 14, no. 7, pp. 599-624, 1999.

[3] W. Lian, S. A. Litherland, H. Badrane et al., "Ultrasensitive detection of biomolecules with fluorescent dye-doped nanoparticles," Analytical Biochemistry, vol. 334, no. 1, pp. 135-144, 2004.

[4] S. Santra, P. Zhang, K. Wang, R. Tapec, and W. Tan, "Conjugation of biomolecules with luminophore-doped silica nanoparticles for photostable biomarkers," Analytical Chemistry, vol. 73, no. 20, pp. 4988-4993, 2001.

[5] O. H. Lowry, N. J. Rosebrough, A. L. Farr, and R. J. Randall, "Protein measurement with the Folin phenol reagent," The Journal of Biological Chemistry, vol. 193, no. 1, pp. 265-275, 1951.

[6] W. Tansub, K. Tuitemwong, S. Thepwiwat, P. Limsuwan, and P. Tuitemwong, "Synthesis of antibodies-conjugated fluorescent dye-doped silica nanoparticles for a rapid single step detection of Campylobacter jejuni in live poultry," Journal of Nanomaterials, vol. 2012, Article ID 865186, 7 pages, 2012.

[7] Malvern Instruments Ltd, Zeta Potential Measurement Using Laser Doppler Electrophoresis (LDE), Innovative Solutions in Material Characterization, Malvern, UK, 2011, http://www.malvern.com/LabEng/technology/zeta_potential/zeta_potential_ LDE.htm.

[8] X. Zhao, L. R. Hilliard, S. J. Mechery et al., "A rapid bioassay for single bacterial cell quantitation using bioconjugated nanoparticles," Proceedings of the National Academy of Sciences of the United States of America, vol. 101, no. 42, pp. 15027-15032, 2004.

[9] I. Abarkan, T. Doussineau, and M. Smaïhi, "Tailored macro/ microstructural properties of colloidal silica nanoparticles via microemulsion preparation," Polyhedron, vol. 25, no. 8, pp. 1763-1770, 2006.

[10] H. Zhao, Y. Li, R. Liu, F. Zhao, and Y. Hu, "Synthesis method for silica needle-shaped nano-hollow structure," Materials Letters, vol. 62, no. 19, pp. 3401-3403, 2008.

[11] M. Zhao, L. Zheng, X. Bai, N. Li, and L. Yu, "Fabrication of silica nanoparticles and hollow spheres using ionic liquid microemulsion droplets as templates," Colloids and Surfaces A, vol. 346, no. 1-3, pp. 229-236, 2009.

[12] J. T. Park, J. A. Seo, S. H. Ahn, J. H. Kim, and S. W. Kang, "Surface modification of silica nanoparticles with hydrophilic polymers," Journal of Industrial and Engineering Chemistry, vol. 16, no. 4, pp. 517-522, 2010.

[13] D. D. Asouhidou, K. S. Triantafyllidis, N. K. Lazaridis, and K. A. Matis, "Adsorption of Remazol Red 3BS from aqueous solutions using APTES- and cyclodextrin-modified HMS-type mesoporous silicas," Colloids and Surfaces A, vol. 346, no. 1-3, pp. 83-90, 2009.

[14] B. Shi, Y. Wang, Y. Guo et al., "Aminopropyl-functionalized silicas synthesized by W/O microemulsion for immobilization of penicillin G acylase," Catalysis Today, vol. 148, no. 1-2, pp. 184-188, 2010.

[15] L. D. White and C. P. Tripp, "Reaction of (3-aminopropyl) dimethylethoxysilane with amine catalysts on silica surfaces," Journal of Colloid and Interface Science, vol. 232, no. 2, pp. 400407, 2000. 

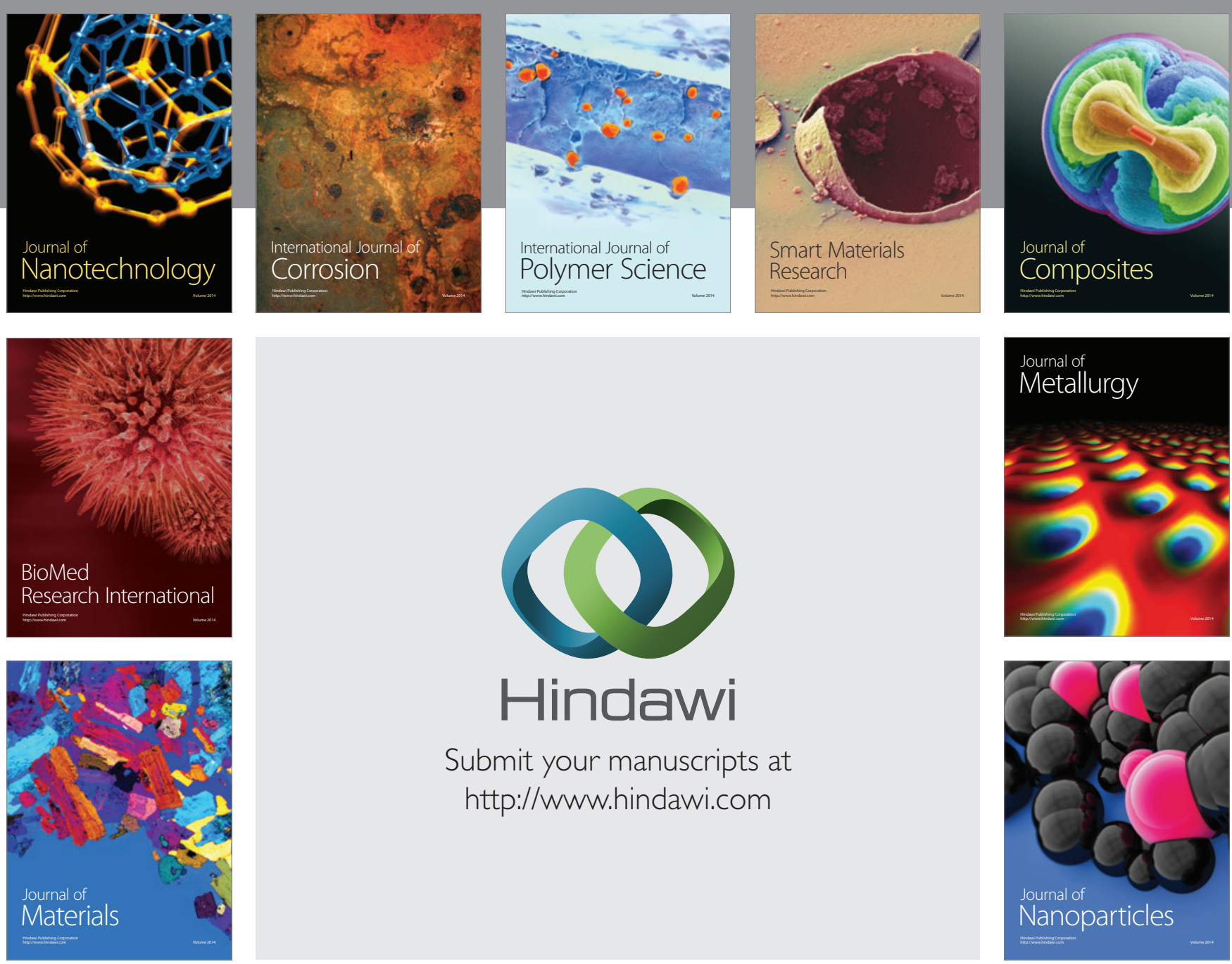

Submit your manuscripts at http://www.hindawi.com
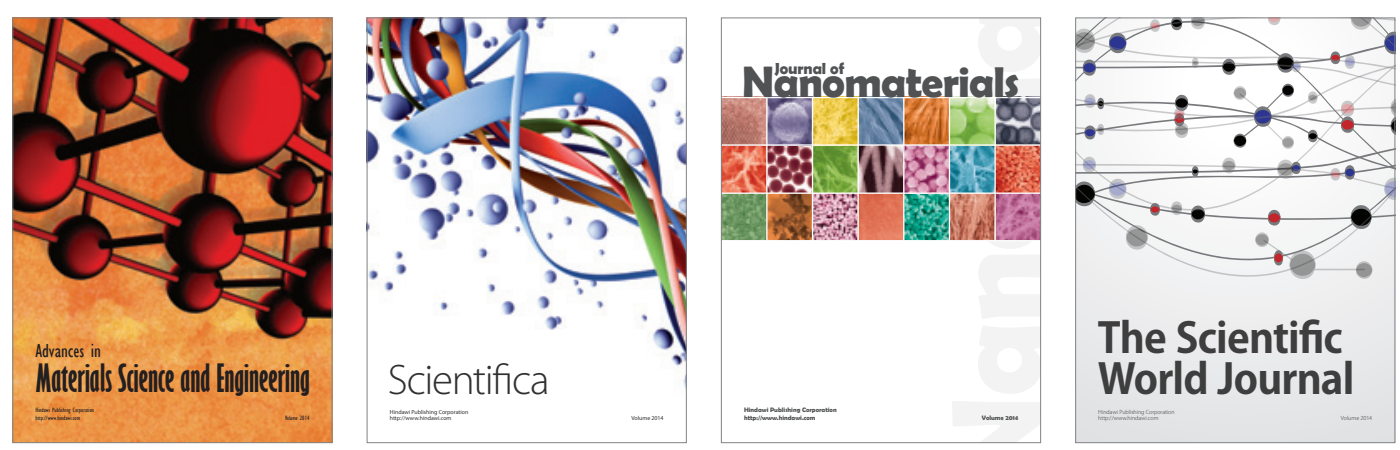

\section{The Scientific World Journal}
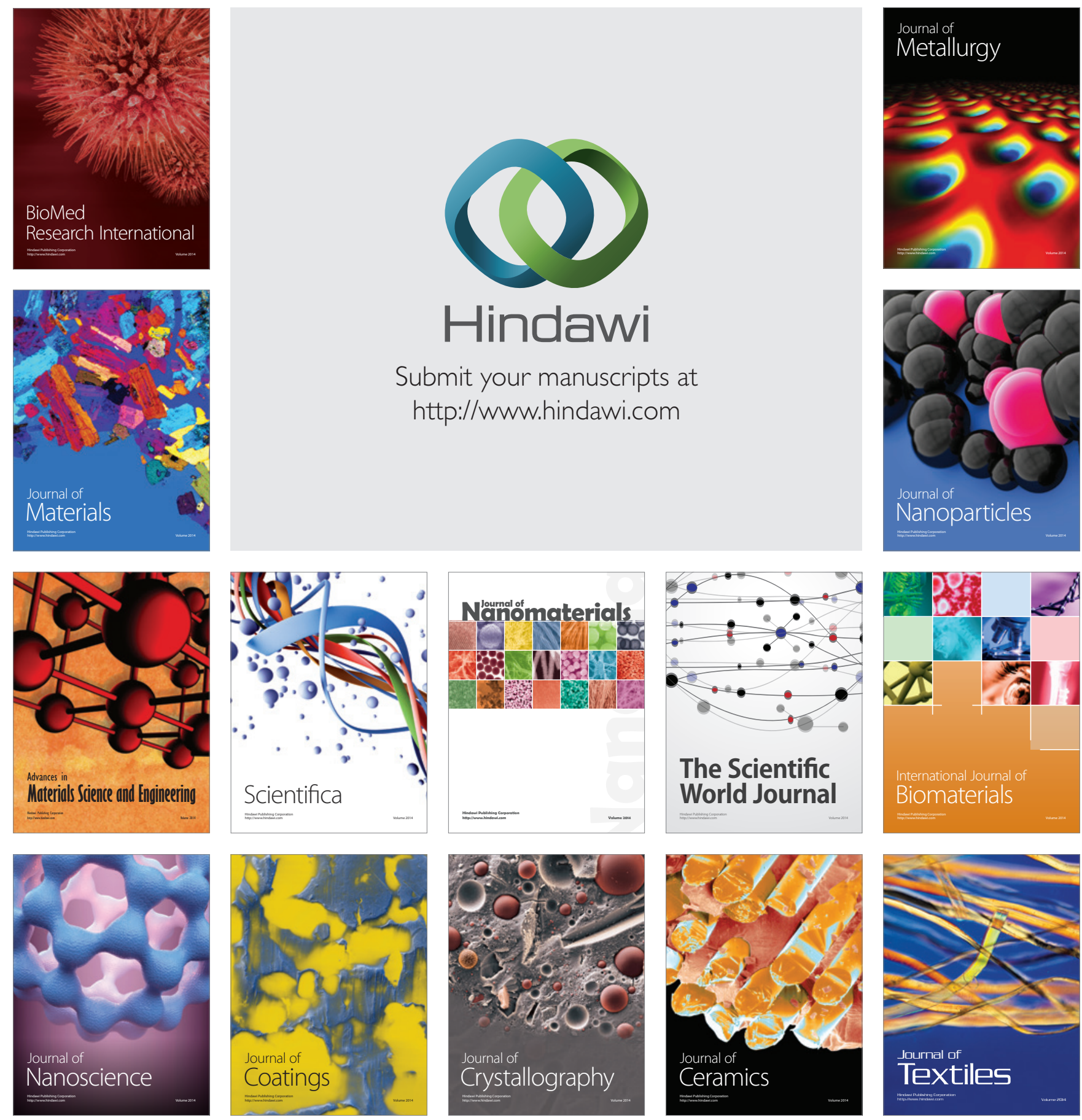